\title{
Major dietary patterns and risk of frailty in older adults: a prospective cohort study
}

\author{
Luz M León-Muñoz ${ }^{1,2^{*}}$, Esther García-Esquinas ${ }^{1,2}$, Esther López-García ${ }^{1,2}$, José R Banegas ${ }^{1,2}$ \\ and Fernando Rodríguez-Artalejo ${ }^{1,2^{*}}$
}

\begin{abstract}
Background: There is emerging evidence of the role of certain nutrients as risk factors for frailty. However, people eat food, rather than nutrients, and no previous study has examined the association between dietary patterns empirically derived from food consumption and the risk of frailty in older adults.

Methods: This is a prospective cohort study of 1,872 non-institutionalized individuals aged $\geq 60$ years recruited between 2008 and 2010. At baseline, food consumption was obtained with a validated diet history and, by using factor analysis, two dietary patterns were identified: a 'prudent' pattern, characterized by high intake of olive oil and vegetables, and a 'Westernized' pattern, with a high intake of refined bread, whole dairy products, and red and processed meat, as well as low consumption of fruit and vegetables. Participants were followed-up until 2012 to assess incident frailty, defined as at least three of the five Fried criteria (exhaustion, weakness, low physical activity, slow walking speed, and unintentional weight loss).
\end{abstract}

Results: Over a 3.5-year follow-up, 96 cases of incident frailty were ascertained. The multivariate odds ratios (95\% confidence interval) of frailty among those in the first (lowest), second, and third tertile of adherence to the prudent dietary pattern were $1,0.64(0.37-1.12)$, and $0.40(0.2-0.81)$, respectively; $P$-trend $=0.009$. The corresponding values for the Westernized pattern were $1,1.53(0.85-2.75)$, and $1.61(0.85-3.03) ; P$-trend $=0.14$. Moreover, a greater adherence to the Westernized pattern was associated with an increasing risk of slow walking speed and weight loss.

Conclusions: In older adults, a prudent dietary pattern showed an inverse dose-response relationship with the risk of frailty while a Westernized pattern had a direct relationship with some of their components. Clinical trials should test whether a prudent pattern is effective in preventing or delaying frailty.

Keywords: Cohort study, Diet, Frailty, Older adults, Spain

\section{Background}

Frailty is a medical syndrome resulting from age-associated impairments in several physiological systems. This syndrome is characterized by a high vulnerability to even minor environmental stressors (e.g., a minor infection), which leads to increased risk of disability, dependency, need for long-term care, and mortality [1]. Given the elevated prevalence of this syndrome [2,3] and its serious consequences, there is substantial interest in the identification of

\footnotetext{
* Correspondence: luz.leon@uam.es; fernando.artalejo@uam.es ${ }^{1}$ CIBER of Epidemiology and Public Health (CIBERESP), Arzobispo Morcillo, s/n 28029, Madrid, Spain ${ }^{2}$ Department of Preventive Medicine and Public Health, School of Medicine, Universidad Autónoma de Madrid / IdiPaz, Arzobispo Morcillo, s/n 28029, Madrid, Spain
}

(c) 2015 León-Muñoz et al.; licensee BioMed Central. This is an Open Access article distributed under the terms of the Creative Commons Attribution License (http://creativecommons.org/licenses/by/4.0), which permits unrestricted use, distribution, and reproduction in any medium, provided the original work is properly credited. The Creative Commons Public Domain Dedication waiver (http://creativecommons.org/publicdomain/zero/1.0/) applies to the data made available in this article, unless otherwise stated.

the risk factors for frailty, as well as in the development of interventions to avoid or delay its onset $[4,5]$.

Emerging evidence suggests that low intake of certain micronutrients and protein could be a risk factor for frailty $[6,7]$. However, people do not eat nutrients; rather, they eat meals consisting of foods with complex combinations of nutrients that may interact. Moreover, intake of several nutrients is usually correlated (e.g., meat protein and saturated fat, vitamin A and C). Therefore, it might be difficult to assess the independent health effect of nutrients. Additionally, the effect of a single nutrient might be too small to be detected, but the joint effect of many nutrients within a dietary pattern could be large enough to be detectable. Accordingly, the investigation of dietary patterns can complement the study of individual nutrients and overcome its potential limitations [8]. 
Two main approaches have been used to describe dietary patterns $[8,9]$. The first approach formulates indices or scales representing the degree of adherence to a prioridefined dietary patterns that are deemed to be healthy according to the prevailing scientific evidence. A good example frequently used in the literature is the Trichopoulou index, which represents the traditional Mediterranean diet [10]. The second approach uses factor or cluster analysis to empirically define a few food patterns that reflect different dietary compositions. These patterns derived $a$ posteriori have the advantage of reflecting existing food habits in the study population. These two approaches address different research questions. For instance, the traditional Mediterranean diet, defined a priori, represents the diet consumed by populations in the Mediterranean basin during the 1960s, whereas a pattern defined a posteriori represents the present-day dietary intake. This is important because, in recent decades, diet in Mediterranean countries has undergone a process of westernization, which includes a large increase in the consumption of red meat, saturated fats and simple carbohydrates, and reduced consumption of whole-grain cereals and legumes [11].

In a recent paper using information from the SeniorsENRICA cohort, we have found that adherence to the Mediterranean diet, as assessed by a priori scales including the Trichopoulou index, was associated with a lower risk of frailty [12]. Further, in previous research, an index of global diet quality [13] and several a priori scales of Mediterranean diet adherence [14-17] have been linked to lower frequency of frailty or some of its components. Herein, we have performed a factor analysis with food consumption data from the Seniors-ENRICA cohort to identify existing dietary patterns in the population. To our knowledge, no previous study has yet examined the association between $a$ posteriori-defined dietary patterns and the risk of frailty in older adults.

\section{Methods}

\section{Study design and population}

Data were taken from the Seniors-ENRICA cohort, whose methods have been previously reported [12,18]. In brief, this cohort was established between 2008 and 2010 with 2,614 non-institutionalized individuals aged 60 years and older. At baseline, information was collected by telephone interview and by a face-to-face questionnaire and a physical examination conducted at the participants' homes. Participants were followed-up until 2012, when a second wave of data collection was performed. Ninety-five participants (3.6\%) died during follow-up; from the remaining 2,519 subjects, 2,085 had complete information on frailty in 2012. Baseline socio-demographic, lifestyle, and clinical characteristics of individuals lost to follow-up and those remaining in the study were similar, although the latter were slightly younger and had higher educational level and less comorbidity.

Study participants gave written informed consent. The study was approved by the Clinical Research Ethics Committee of the University Hospital La Paz in Madrid.

\section{Study variables \\ Dietary patterns derived from food consumption data}

At baseline, food consumption was assessed with a validated computerized dietary history which was developed from that used in the EPIC-cohort study in Spain $[19,20]$. This instrument registered the consumption of 880 foods in the preceding year, and quantification of food portions was aided by a set of photographs.

To identify dietary patterns, the 880 foods were categorized into 36 different groups according to similarities in nutrient profile. We applied factor analysis (principal components analysis) to these food groups to generate various independent dietary patterns (factors) made up of foods with a high degree of inter-correlation [21]. The factors were rotated by orthogonal transformation (Varimax rotation) to facilitate their interpretation. Dietary patterns to be retained for future analysis took into account their ease of interpretation, and required an eigenvalue of $\geq 1.5$ on the scree test [22]. Factor loadings were obtained for each food group to identify the groups most closely correlated with the dietary pattern (Table 1). Two patterns were identified. The first was called the 'prudent' pattern (PP) due to the high consumption of olive oil, vegetables, potatoes, legumes, blue fish, pasta, and meat; and the second was called the 'Westernized' pattern (WP) because of the high consumption of refined bread, whole dairy products, and red and processed meat, as well as the low intake of whole grains, fruit, low-fat dairy, and vegetables. For each pattern, each subject received a score that was calculated as the sum of the intakes in each food group weighted by the corresponding factor loading. A higher score indicated a higher adherence to the respective dietary pattern.

\section{Frailty}

At baseline and at the end of follow-up, we used a slight modification of the operational definition of frailty developed in the Cardiovascular Health Study by Fried et al. [23]. Specifically, frailty was defined as having three or more of the following five criteria: i) Exhaustion: any of the following responses to two questions taken from the CES-D scale [24]: "I felt that everything I did was an effort" and "I could not get going" at least 3 to 4 days a week. ii) Weakness: the lowest quintile in our study sample for maximum strength on the dominant hand adjusted for sex and body mass index (BMI). Strength was measured as the highest of two consecutive measures with a Jamar dynamometer $[25,26]$. iii) Low physical activity: 
Table 1 Factor-loading matrix for dietary patterns among the non-frail population at baseline

\begin{tabular}{|c|c|c|}
\hline & $\begin{array}{l}\text { Prudent } \\
\text { pattern }\end{array}$ & $\begin{array}{l}\text { Westernized } \\
\text { pattern }\end{array}$ \\
\hline \multicolumn{3}{|l|}{ Foods } \\
\hline Olive oil & 0.726 & * \\
\hline Non-leafy vegetables & 0.608 & -0.303 \\
\hline Leafy vegetables & 0.539 & -0.228 \\
\hline $\begin{array}{l}\text { Potatoes (other than French fries) and other } \\
\text { tuber products }\end{array}$ & 0.418 & * \\
\hline Legumes (non-soy-derived products) & 0.394 & * \\
\hline Blue fish & 0.341 & * \\
\hline Pasta & 0.314 & 0.185 \\
\hline Sauces & 0.313 & 0.200 \\
\hline Poultry and other unprocessed white meat & 0.280 & -0.163 \\
\hline Refined grains and breakfast cereals & 0.268 & * \\
\hline Non-blue fish and seafood & 0.266 & -0.152 \\
\hline Eggs & 0.214 & 0.194 \\
\hline Nuts and oily seeds & 0.184 & * \\
\hline $\begin{array}{l}\text { Water, infusions, non-sweetened non-alcoholic } \\
\text { beverages }\end{array}$ & * & * \\
\hline Preserved fruits and olives & * & * \\
\hline Refined bread products & 0.264 & 0.543 \\
\hline Whole dairy products & * & 0.397 \\
\hline French fries & 0.247 & 0.382 \\
\hline Red and processed meat & 0.246 & 0.379 \\
\hline Sugar and honey & * & 0.334 \\
\hline Beer, wine and cider & * & 0.304 \\
\hline Pastries & * & 0.299 \\
\hline Non-olive oils & * & 0.284 \\
\hline Sweetened non-alcoholic beverages & * & 0.278 \\
\hline Hard liquor (whisky, gin, rum, brandy, vodka) & * & 0.222 \\
\hline Appetizers & * & 0.174 \\
\hline Biscuits & * & * \\
\hline Butter, margarine and lard & * & * \\
\hline Organ meats & * & * \\
\hline Coffee and tea & * & * \\
\hline Chocolate and cocoa & * & * \\
\hline $\begin{array}{l}\text { Other sweets (jam, jelly, marzipan, candies) } \\
\text { and sweetener }\end{array}$ & * & * \\
\hline Soy-derived products & * & * \\
\hline Low-fat dairy products & * & -0.363 \\
\hline Fresh fruit and fruit juices & * & -0.391 \\
\hline Whole grain products & * & -0.430 \\
\hline
\end{tabular}

*Correlation coefficient between 0.15 and $-0.15 ; n=1,872$.

lowest quintile in our sample (walking $\leq 2.5 \mathrm{~h} /$ week in men and $\leq 2 \mathrm{~h} /$ week in women). iv) Slow walking speed: the lowest quintile in our study sample for the three- meter walking speed test, adjusted for sex and height $[26,27]$. v) Weight loss: involuntary loss of $\geq 4.5 \mathrm{~kg}$ of body weight in the preceding year.

\section{Potential confounders}

At baseline, information was gathered on sociodemographic variables, lifestyle, and diseases that could act as confounders of the study association because of their relation to both diet and frailty. Specifically, study participants were asked about their sex, age, educational level, the last occupation held, tobacco consumption, number of medications used, and energy intake (calculated with standard food composition tables). Occupation was coded according to the National Classification of Occupations in Spain, and was classified into four classes: I (professionals, managers, proprietors, and clerical workers); II (self-employed farm workers); III (skilled and unskilled manual workers); and IV (paid farm workers). Housewives were assigned the occupation of their husband. Study participants also reported the following physician-diagnosed diseases: cardiovascular disease (myocardial infarction, stroke, heart failure), diabetes mellitus, cancer at any site, asthma or chronic bronchitis, osteomuscular disease (osteoarthritis, arthritis, hip fracture), and depression requiring drug treatment. Weight and height were measured in standardized conditions [28] and the BMI was calculated as weight in kg divided by square of height in $\mathrm{m}$. Lastly, cognitive function was assessed with the Mini-Mental State Examination [29] and limitations in instrumental activities of daily living (IADL) were ascertained with the Lawton-Brody questionnaire [30].

\section{Statistical analysis}

From the 2,085 individuals who were followed-up, we excluded 174 who were frail or lacked data on frailty at baseline, 7 with missing data on diet, and 32 without data on potential confounders. Therefore, the analyses were conducted on 1,872 individuals.

The association between dietary patterns and risk of frailty was summarized with odds ratios (OR) and their 95\% confidence interval (CI) obtained from logistic regression. Two logistic models were built: the first one adjusted for the baseline number of frailty criteria, sex, age, education, and occupation, and the second model additionally adjusted for the rest of the variables described above. Adherence to empirically-derived dietary patterns was classified into tertiles, and the lowest tertile was used as the reference group. $P$ values for linear trend were calculated by modeling tertiles of the dietary patterns as a continuous variable.

We ran several sensitivity analyses to assess the robustness of the main results. Given that the study aimed to evaluate the association between diet and frailty, we 
repeated the analysis excluding the weight loss criterion from the definition of frailty [14]. Thus, in this analysis frailty was defined as having at least two of the four remaining Fried criteria. Also, we replicated the analyses after excluding the following individuals: i) those reporting severe or substantial difficulty in chewing or eating at the end of follow-up; ii) those with diagnosed disease at baseline (cardiovascular disease, diabetes, cancer, chronic lung disease, or depression requiring treatment); and iii) those with baseline limitation in IADL.

Finally, we used the same type of modeling to assess the association between dietary patterns and the risk of each frailty criterion among robust individuals (free of all five of Fried's criteria) at baseline.

Statistical significance was set at two-sided $P<0.05$. The analyses were performed with Stata ${ }^{\oplus}$, version 11.1.

\section{Results}

Compared to individuals in the first (lowest) tertile of the PP, those in the third tertile were younger, had a higher energy intake, and there was a lower percentage of smokers, persons diagnosed with diabetes or depression, and with limitations in IADL; however, there was a higher percentage of individuals with $B M I \geq 30 \mathrm{~kg} / \mathrm{m}^{2}$ and reporting osteomuscular disease. However, it should be noted that for depression, IADL limitation, and BMI, the data did not suggest a linear association with the PP. As regards the WP, those in the third tertile were younger and showed a higher energy intake, there was a greater percentage of smokers and individuals with limitation in IADL, and a lower percentage of subjects with university education and osteomuscular disease (Table 2). Nevertheless, for IADL limitation and university education, we found no indication of a linear association with the WP.

During a mean follow-up of 3.5 years, we ascertained 96 cases of incident frailty. Table 3 shows the association between adherence to the dietary patterns and the risk of frailty. Results from models with partial (model 1) and full (model 2) adjustment were rather similar, and showed that the PP was inversely associated with the risk of frailty while the WP had a non-statistically significant tendency to a higher risk. In model 2, the OR (95\% CI) of frailty among those in the first, second, and third tertile of adherence to the PP were 1, 0.64 (0.371.12 ), and $0.40(0.2-0.81)$, respectively; $P$-trend $=0.009$. The corresponding values for the WP were $1,1.53(0.85-$ $2.75)$, and $1.61(0.85-3.03)$; $P$-trend $=0.14$. For both patterns, these results were similar to those obtained in all the sensitivity analyses.

Finally, a greater adherence to the PP showed a nonstatistically significant tendency to a lower risk of exhaustion and of slow walking speed (Table 4). However, the WP did show an association with an increasing risk of slow walking speed and weight loss. Specifically, the OR (95\% CI) of slow walking speed across tertiles of the WP were $1,1.15$ (0.74-1.76), and 1.85 (1.19-2.87); $P$-trend = 0.007 . For weight loss, the corresponding values were 1 , $1.37(0.77-2.41)$, and $2.12(1.22-3.70) ; P$-trend $=0.007$. Results for the association between the WP and exhaustion and low physical activity were in the same direction but did not reach statistical significance (Table 4).

\section{Discussion}

Our results show that adherence to a PP, characterized by high intake of olive oil and vegetables, had an inverse dose-response relationship with frailty; in contrast, an increasing adherence to the WP, characterized by high intake of refined cereals, whole dairy, and red and processed meat, was associated with increased the risk of slow walking speed and weight loss.

Previous population-based surveys and cohort studies with selected samples have found dietary patterns consistent with the PP, which has also been called the 'healthy' or 'whole food' pattern, and with the WP, also called the 'processed food' pattern. As in our study, the PP has usually been associated with a healthier lifestyle, while the WP has been linked to less healthy behaviors [31,32].

In cohort studies, the PP has been associated with lower risk of coronary disease [31,33] and diabetes [34]. It has also shown an inverse cross-sectional association with the metabolic syndrome and insulin resistance [35], as well as with levels of numerous biomarkers of inflammation and cardiovascular risk [32,36]. Moreover, some studies have found the PP to be associated with lower risk of cognitive impairment [37,38] and depression $[39,40]$; however, a cross-sectional study found no association with cognitive function [41] and in one prospective investigation the protection against depression, was restricted to individuals older than 60 years [42]. As regards the WP, it has been linked to higher risk of coronary disease [31,33], diabetes [34], metabolic syndrome, and insulin resistance [35]. There is also evidence that the WP is associated with higher levels of cardiometabolic biomarkers, including insulin, C-peptide, leptin, homocysteine, and inflammation mediators (sTNFR2, IL-6, CRP, E-selectin) $[34,36,43]$. Finally, the WP has been related to an increased risk of poor cognition [37,41], while some [39], but not all studies [40,42], have reported a higher risk of depression. Given that obesity [44], systemic inflammation [45-47], cardiovascular disease [2], poor cognitive function [48,49], and depression [50] are all well-known risk factors of frailty, all these health disorders could contribute to the association between the PP, the WP, and frailty.

There is evidence that healthy diets, which are consistent with the PP in our study, may reduce the risk of 
Table 2 Characteristics of the non-frail population at baseline, by adherence to the dietary patterns

\begin{tabular}{|c|c|c|c|c|c|c|c|c|}
\hline & \multicolumn{4}{|c|}{ Prudent pattern } & \multicolumn{4}{|c|}{ Westernized pattern } \\
\hline & Tertile 1 & Tertile 2 & Tertile 3 & $P$ value & Tertile 1 & Tertile 2 & Tertile 3 & $P$ value \\
\hline $\mathrm{n}$ & 620 & 627 & 625 & & 624 & 625 & 623 & \\
\hline Number of frailty components, mean (SE) & $0.3(0.1)$ & $0.3(0.1)$ & $0.2(0.1)$ & $<0.01$ & $0.2(0.1)$ & $0.3(0.1)$ & $0.3(0.1)$ & $<0.01$ \\
\hline Sex, women, \% & 51.1 & 51.8 & 51.8 & 0.53 & 51.6 & 51.5 & 51.5 & 0.55 \\
\hline Age, years, mean (SE) & $70.1(0.3)$ & $68.4(0.3)$ & $67.6(0.3)$ & $<0.01$ & $69.2(0.3)$ & $68.7(0.3)$ & $68.2(0.3)$ & 0.02 \\
\hline \multicolumn{9}{|l|}{ Educational level, \% } \\
\hline$\leq$ Primary & 56.7 & 48.4 & 56.4 & $<0.01$ & 51.7 & 56.3 & 53.6 & $<0.01$ \\
\hline Secondary & 22.9 & 27.4 & 24.8 & & 24.2 & 25.2 & 25.7 & \\
\hline University & 20.4 & 24.2 & 18.8 & & 24.2 & 18.5 & 20.7 & \\
\hline \multicolumn{9}{|l|}{ Occupational social class, \% } \\
\hline I (Professionals, managers, proprietors and clerical workers) & 61.9 & 66.0 & 63.0 & 0.04 & 66.7 & 60.5 & 63.7 & 0.07 \\
\hline II (Self-employed farm workers) & 2.1 & 2.7 & 4.4 & & 2.7 & 3.4 & 3.1 & \\
\hline III (Skilled and unskilled manual workers) & 34.5 & 30.2 & 31.5 & & 29.7 & 35.0 & 31.4 & \\
\hline IV (Paid farm workers) & 1.5 & 1.1 & 1.1 & & 0.9 & 1.1 & 1.8 & \\
\hline \multicolumn{9}{|l|}{ Tobacco, \% } \\
\hline Never smoker & 61.6 & 59.1 & 60.3 & $<0.01$ & 63.9 & 60.9 & 56.1 & $<0.01$ \\
\hline Former smoker & 25.5 & 29.4 & 30.4 & & 29.6 & 26.4 & 29.2 & \\
\hline Current smoker & 12.9 & 11.5 & 9.3 & & 6.5 & 12.7 & 14.6 & \\
\hline \multicolumn{9}{|l|}{ Body mass index, $\mathrm{kg} / \mathrm{m}^{2}, \%$} \\
\hline$<25$ & 19.5 & 18.6 & 20.1 & 0.002 & 20.8 & 18.8 & 18.5 & 0.01 \\
\hline $25-29.9$ & 49.6 & 53.4 & 46.5 & & 49.6 & 50.6 & 49.4 & \\
\hline$\geq 30$ & 30.8 & 28.0 & 33.4 & & 29.6 & 30.5 & 32.1 & \\
\hline Energy intake, kcal/d, mean (SE) & $1731(18)$ & $2009(18)$ & $2358(18)$ & $<0.01$ & $1854(19)$ & $1922(19)$ & $2324(19)$ & $<0.01$ \\
\hline Mini-Mental State Examination, mean (SE) & $27.8(0.1)$ & $28.2(0.1)$ & $28.2(0.1)$ & $<0.01$ & $28.2(0.1)$ & $28.1(0.1)$ & $27.9(0.1)$ & $<0.01$ \\
\hline Eating difficulties, \% & 3.3 & 2.9 & 2.6 & 0.11 & 2.5 & 2.3 & 4.0 & 0.03 \\
\hline \multicolumn{9}{|l|}{ Diagnosed diseases, \% } \\
\hline Cardiovascular disease $^{a}$ & 4.9 & 4.4 & 5.1 & 0.005 & 5.7 & 4.2 & 4.5 & 0.002 \\
\hline Diabetes & 13.0 & 11.9 & 9.7 & $<0.01$ & 12.2 & 10.1 & 12.2 & $<0.01$ \\
\hline Cancer & 1.2 & 2.1 & 2.2 & 0.19 & 2.0 & 1.8 & 1.7 & 0.42 \\
\hline Asthma or chronic bronchitis & 7.5 & 7.8 & 7.1 & 0.15 & 7.5 & 8.2 & 6.8 & 0.12 \\
\hline Osteomuscular disease ${ }^{b}$ & 43.5 & 47.6 & 49.8 & $<0.01$ & 48.1 & 47.9 & 44.9 & $<0.01$ \\
\hline Depression needing treatment & 7.4 & 4.6 & 4.8 & $<0.01$ & 5.2 & 5.3 & 6.2 & $<0.01$ \\
\hline Limitation in IADL, \% & 9.0 & 6.0 & 7.5 & $<0.01$ & 6.8 & 6.7 & 8.9 & $<0.01$ \\
\hline Number of treatments, mean (SE) & $2.1(0.1)$ & $1.9(0.1)$ & $1.9(0.1)$ & $<0.01$ & $2.2(0.1)$ & $1.8(0.1)$ & $1.8(0.1)$ & $<0.01$ \\
\hline
\end{tabular}

SE, Standard error; IADL, Instrumental activities of daily living. Values are adjusted for sex and age. $P$ values in Table 2 test differences between the three tertile groups, based on $\mathrm{X}^{2}$ or ANOVA tests, as appropriate.

${ }^{\mathrm{a}}$ Ischemic heart disease, stroke, and heart failure; ${ }^{\mathrm{b}}$ Osteoarthritis, arthritis, and hip fracture; $\mathrm{n}=1,872$.

several components of frailty. Specifically, a diet rich in vegetables, whole grains, and blue fish has been associated with higher grip strength in older adults [51]. Further, a healthy diet has been shown to protect against slow walking speed [13-17], unintentional weight loss $[14,15]$, low physical activity $[13,14]$, and muscle weakness [6]. Despite the clear inverse association between the PP and frailty in our study, the PP did not evidence a statistically significant association with any of its components, though it showed some tendency to reduce the risk of exhaustion and slow walking speed. This suggests that the protective effect of the PP on frailty might result from synergic benefits on each component of frailty, which are nevertheless too small to be detectable when assessed separately. We are not aware of previous investigations on the effect of the WP on frailty or its components; in our 
Table 3 Association between dietary patterns and risk of frailty during a 3.5-year follow-up of older adults

\begin{tabular}{|c|c|c|c|c|c|c|c|c|}
\hline & \multicolumn{4}{|c|}{ Prudent pattern } & \multicolumn{3}{|c|}{ Westernized pattern } & \multirow[b]{3}{*}{$P$-trend } \\
\hline & Tertile 1 & Tertile 2 & Tertile 3 & & Tertile 1 & Tertile 2 & Tertile 3 & \\
\hline & & $\begin{array}{l}\text { Odds ratio } \\
(95 \% \mathrm{Cl})\end{array}$ & $\begin{array}{l}\text { Odds ratio } \\
(95 \% \mathrm{Cl})\end{array}$ & $P$-trend & & $\begin{array}{l}\text { Odds ratio } \\
(95 \% \mathrm{Cl})\end{array}$ & $\begin{array}{l}\text { Odds ratio } \\
(95 \% \mathrm{Cl})\end{array}$ & \\
\hline \multicolumn{9}{|l|}{ Main analysis } \\
\hline Number of frailty events & 48 & 27 & 21 & & 24 & 35 & 37 & \\
\hline Model 1 & Ref. & $0.69(0.41-1.17)$ & $0.59(0.33-1.04)$ & 0.05 & Ref. & $1.53(0.87-2.72)$ & $1.61(0.91-2.84)$ & 0.11 \\
\hline Model 2 & Ref. & $0.64(0.37-1.12)$ & $0.40(0.20-0.81)^{*}$ & 0.009 & Ref. & $1.53(0.85-2.75)$ & $1.61(0.85-3.03)$ & 0.14 \\
\hline \multicolumn{9}{|l|}{ Sensitivity analyses } \\
\hline \multicolumn{9}{|c|}{$\begin{array}{l}\text { Excluding weight loss from the } \\
\text { definition of frailty }\end{array}$} \\
\hline Number of frailty events & 102 & 78 & 62 & & 71 & 81 & 90 & \\
\hline Model 1 & Ref. & $0.80(0.57-1.13)$ & $0.72(0.50-1.03)$ & 0.07 & Ref. & $1.23(0.86-1.76)$ & $1.43(1.00-2.03)^{*}$ & 0.04 \\
\hline Model 2 & Ref. & $0.83(0.58-1.18)$ & $0.67(0.44-1.02)$ & 0.06 & Ref. & $1.27(0.88-1.83)$ & $1.53(1.03-2.26)^{*}$ & 0.03 \\
\hline \multicolumn{9}{|c|}{$\begin{array}{l}\text { Excluding } 58 \text { individuals with } \\
\text { eating difficulty }\end{array}$} \\
\hline Number of frailty events & 40 & 23 & 13 & & 20 & 31 & 31 & \\
\hline Model 1 & Ref. & $0.70(0.40-1.23)$ & $0.63(0.34-1.15)$ & 0.11 & Ref. & $1.69(0.92-3.13)$ & $1.61(0.87-2.98)$ & 0.14 \\
\hline Model 2 & Ref. & $0.64(0.35-1.18)$ & $0.40(0.19-0.84)^{*}$ & 0.01 & Ref. & $1.64(0.87-3.11)$ & $1.45(0.73-2.90)$ & 0.28 \\
\hline \multicolumn{9}{|c|}{$\begin{array}{l}\text { Excluding } 543 \text { individuals with } \\
\text { diagnosed severe diseases }\end{array}$} \\
\hline Number of frailty events & 29 & 12 & 10 & & 14 & 19 & 18 & \\
\hline Model 1 & Ref. & $0.54(0.26-1.13)$ & $0.48(0.22-1.05)$ & 0.05 & Ref. & $1.30(0.61-2.76)$ & $1.34(0.62-2.87)$ & 0.46 \\
\hline Model $2^{\mathrm{a}}$ & Ref. & $0.52(0.24-1.16)$ & $0.34(0.13-0.89)^{*}$ & 0.02 & Ref. & $1.23(0.57-2.67)$ & $1.44(0.63-3.29)$ & 0.38 \\
\hline \multicolumn{9}{|c|}{$\begin{array}{l}\text { Excluding } 182 \text { individuals with } \\
\text { limitation in } I A D L^{b}\end{array}$} \\
\hline Number of frailty events & 32 & 17 & 10 & & 15 & 22 & 22 & \\
\hline Model 1 & Ref. & $0.55(0.29-1.03)$ & $0.40(0.19-0.85)^{*}$ & 0.01 & Ref. & $1.56(0.78-3.10)$ & $1.39(0.69-2.80)$ & 0.37 \\
\hline Model 2 & Ref. & $0.49(0.25-0.98)^{*}$ & $0.26(0.11-0.63)^{* *}$ & 0.002 & Ref. & $1.70(0.84-3.44)$ & $1.36(0.63-2.94)$ & 0.40 \\
\hline
\end{tabular}

$\mathrm{Cl}$, Confidence interval; IADL, Instrumental activities of daily living; ${ }^{*} P<0.05,{ }^{* *} P<0.01$.

Model 1: Adjusted for number of frailty components at baseline $(0,1,2)$, sex, age, educational level ( $\leq$ primary, secondary, university), and occupation (social class I, II, III, IV).

Model 2: Adjusted additionally for tobacco (never smoker, former smoker, current smoker), body mass index $\left(\mathrm{kg} / \mathrm{m}^{2}\right)$, energy intake $(\mathrm{kcal} / \mathrm{d})$, cardiovascular disease, diabetes mellitus, cancer, asthma or chronic bronchitis, osteomuscular disease, depression requiring treatment, number of drug treatments, and score on the Mini-Mental State Examination.

${ }^{a}$ As model 2 above but without adjustment for cardiovascular disease, diabetes mellitus, cancer, asthma or chronic bronchitis, and depression requiring treatment; ${ }^{\mathrm{b}}$ Another 28 individuals had missing data on IADL; $\mathrm{n}=1,872$.

study, this pattern was directly associated with several frailty components, in particular slow walking speed and weight loss.

Although the Mediterranean diet, as assessed by a priori scales such as the Trichopoulou index [10,12], and the PP empirically identified in this study share a high consumption of olive oil and vegetables, there are substantial differences between these two dietary patterns. Specifically, some foods which are typical of the Mediterranean diet are not part of the PP. This is the case for fruits and alcoholic beverages (e.g., wine). The reverse situation is also true, so that consumption of white and red meat contributes to the PP, while consumption of any type of meat scores negatively in the Trichopoulou index; moreover, consumption of potatoes is a component of the PP but not of the traditional Mediterranean diet. As a result, the correlation between the PP and the Trichopoulou index was modest (Pearson $r=0.37$ ) in our study sample.

Our results are unique in showing that, despite changes in the traditional diet in Spain derived from the socioeconomic development and modern living arrangements during the last decades [11], a PP characterized by intake of olive oil and vegetables, and also potatoes and meat, protects from the frailty syndrome in older adults. Of particular note is that the PP does not include alcoholic beverages; this is important because, in some studies, alcohol intake has been identified as one of the main contributors to the health benefits of the 
Table 4 Association between dietary patterns and risk of each frailty criterion during a 3.5-year follow-up of robust older adults at baseline

\begin{tabular}{|c|c|c|c|c|c|c|c|c|}
\hline & \multicolumn{4}{|c|}{ Prudent pattern } & \multicolumn{3}{|c|}{ Westernized pattern } & \multirow[b]{2}{*}{$P$-trend } \\
\hline & Tertile 1 & Tertile 2 & Tertile 3 & $P$-trend & Tertile 1 & Tertile 2 & Tertile 3 & \\
\hline \multicolumn{9}{|l|}{ Frailty criteria } \\
\hline Exhaustion, $n$ events & 57 & 42 & 39 & & 40 & 50 & 48 & \\
\hline Odds ratio $(95 \% \mathrm{Cl})$ & Ref. & $0.83(0.53-1.30)$ & $0.75(0.44-1.26)$ & 0.27 & Ref. & $1.40(0.89-2.21)$ & $1.58(0.96-2.58)$ & 0.07 \\
\hline Low physical activity, $\mathrm{n}$ events & 53 & 80 & 68 & & 52 & 70 & 79 & \\
\hline Odds ratio $(95 \% \mathrm{Cl})$ & Ref. & $1.46(0.99-2.17)$ & $0.95(0.61-1.50)$ & 0.77 & Ref. & $1.38(0.98-2.04)$ & $1.46(0.96-2.21)$ & 0.08 \\
\hline Slow walking speed, $n$ events & 71 & 64 & 56 & & 56 & 55 & 80 & \\
\hline Odds ratio $(95 \% \mathrm{Cl})$ & Ref. & $0.83(0.55-1.25)$ & $0.74(0.46-1.18)$ & 0.20 & Ref. & $1.15(0.74-1.76)$ & $1.85(1.19-2.87)^{*}$ & 0.007 \\
\hline Weight loss, $n$ events & 34 & 29 & 40 & & 24 & 30 & 49 & \\
\hline Odds ratio $(95 \% \mathrm{Cl})$ & Ref. & $0.76(0.44-1.30)$ & $0.80(0.46-1.41)$ & 0.46 & Ref. & $1.37(0.77-2.41)$ & $2.12(1.22-3.70)^{*}$ & 0.007 \\
\hline Muscle weakness, $n$ events & 95 & 75 & 68 & & 90 & 77 & 71 & \\
\hline Odds ratio $(95 \% \mathrm{Cl})$ & Ref. & $0.93(0.64-1.35)$ & $0.95(0.62-1.46)$ & 0.81 & Ref. & $1.01(0.70-1.45)$ & $1.09(0.73-1.63)$ & 0.68 \\
\hline
\end{tabular}

$\mathrm{Cl}$, Confidence interval; * $P<0.01$.

Analyses adjusted as in model 2 in Table $3 ; n=1,486$.

Mediterranean diet [52,53]. Given that older adults frequently consume alcohol-interacting medications and are particularly vulnerable to the effects of alcohol [54], they can be reassured that a PP which does not contain wine or any other alcoholic beverage is a healthy dietary option. Lastly, the PP includes all types of meat (white, red, and processed), which is an important source of protein. This is consistent with the emerging evidence of the protective effect of protein intake on frailty [1,7].

This work has several strengths and limitations. Among the former was the prospective design with a sufficient duration to allow for ascertaining a good number of frailty cases. Indeed, there is evidence from clinical trials that the Mediterranean diet lowers the risk of cardiovascular disease in the first few months post-intervention [55,56]; also, previous studies on frailty found a protective effect of the Mediterranean diet after only a few years of follow-up $[14,17]$. Other strengths were that diet was assessed with a validated instrument and that the results were robust in the sensitivity analyses.

The main limitation was that diet was self-reported. Although we used a validated diet history, we cannot rule out some recall bias. This bias may particularly affect individuals with severe diseases and poor cognition, but the results did not change substantially after excluding these subjects from the analysis. Moreover, recall bias usually leads to underestimation of the study association; nevertheless, it did not impede observation of clear associations between the PP, the WP, and frailty. A further limitation was that factor analysis necessarily involves several arbitrary decisions, including the consolidation of food items into food groups, the number of factors to extract, the method of rotation, and the labeling of the dietary patterns [57]. However, the observed patterns are consistent with those found in studies in other countries $[8,31]$. Finally, although the analyses accounted for a good number of potential confounders, some residual confounding cannot be ruled out because we only used rather crude measures of depression (diagnosed disease requiring treatment) and cognitive functioning (the Mini-Mental State Examination).

\section{Conclusions}

In this prospective cohort of community-dwelling older adults, two independent dietary patterns derived from consumption data have been shown to predict frailty. Specifically, a PP pattern showed a protective association with frailty while a WP evinced an increased risk of two frailty components: slow walking speed and weight loss. These findings are of practical relevance, first, because they alert us to the fact that the progressive Westernization of the traditional diet in Spain over the last decades [58] may contribute to increased rates, not only of chronic diseases, but also of frailty and its ensuing disability. This may put additional pressure on the already overburdened health and social services. The National Strategy for Nutrition, Physical Activity and Prevention of Obesity in Spain [59] must tackle this issue. Second, they indicate that clinical trials should test whether dietary interventions to adopt a $\mathrm{PP}$ and to move away from the WP can be effective in avoiding or delaying frailty.

\section{Abbreviations}

BMI: Body mass index; Cl: Confidence interval; IADL: Instrumental activities of daily living; OR: Odds ratio; PP: Prudent dietary pattern; WP: Westernized dietary pattern.

\section{Competing interests}

The authors declare that they have no competing interests. 


\section{Authors' contributions}

LLM and FRA had full access to all of the data in the study and take responsibility for the integrity of the data and the accuracy of the data analysis. Study concept and design: LLM, EGE, ELG, JRB, and FRA. Acquisition of data: LLM, ELG, JRB, and FRA. Statistical analysis: LLM, EGE and FRA. Interpretation of data: LLM, EGG, ELG, JRB, and FRA. Drafting the manuscript: LLM and FRA. Critical revision of the manuscript for important intellectual content: LLM, EGG, ELG, JRB, and FRA. Obtained funding: ELG, JRB, and FRA. Study supervision: FRA. All authors have read and approved the final manuscript.

\section{Acknowledgments}

Baseline data collection was funded by Sanofi-Aventis. Data collection during follow-up was funded by the Spanish Government grants 09/1626 and 09/0104 (Ministry of Health of Spain). Funding specific for this analysis was obtained from the Spanish Government grant 12/1166 (Ministry of Health of Spain) and the FP7-HEALTH-2012-Proposal No: 305483-2 (FRAILOMIC Initiative). Funders had no role in data analyses, preparation of the manuscript, or in the decision to submit it for publication.

Received: 26 August 2014 Accepted: 11 December 2014 Published online: 20 January 2015

\section{References}

1. Morley JE, Vellas B, van Kan GA, Anker SD, Bauer JM, Bernabei R, et al. Frailty consensus: a call to action. J Am Med Dir Assoc. 2013;14:392-7.

2. Collard RM, Boter H, Schoevers RA, Oude Voshaar RC. Prevalence of frailty in community-dwelling older persons: a systematic review. J Am Geriatr Soc. 2012;60:1487-92

3. Santos-Eggimann B, Cuénoud P, Spagnoli J, Junod J. Prevalence of frailty in middle-aged and older community-dwelling Europeans living in 10 countries. J Gerontol A Biol Sci Med Sci. 2009;64:675-81.

4. Woods NF, LaCroix AZ, Gray SL, Aragaki A, Cochrane BB, Brunner RL, et al. Frailty: emergence and consequences in women aged 65 and older in the Women's Health Initiative Observational Study. J Am Geriatr Soc. 2005;53:1321-30.

5. Clegg A, Young J, lliffe S, Rikkert MO, Rockwood K. Frailty in elderly people. Lancet. 2013;381:752-62.

6. Bartali B, Frongillo EA, Bandinelli S, Lauretani F, Semba RD, Fried LP, et al. Low nutrient intake is an essential component of frailty in older persons. J Gerontol A Biol Sci Med Sci. 2006;61:589-93.

7. Beasley JM, LaCroix AZ, Neuhouser ML, Huang Y, Tinker L, Woods N, et al. Protein intake and incident frailty in the Women's Health Initiative observational study. J Am Geriatr Soc. 2010;58:1063-71.

8. Hu FB. Dietary pattern analysis: a new direction in nutritional epidemiology. Curr Opin Lipidol. 2002;13:3-9.

9. Guallar-Castillón P, Rodríguez-Artalejo F, Tormo MJ, Sánchez MJ, Rodríguez $\mathrm{L}$, Quirós JR, et al. Major dietary patterns and risk of coronary heart disease in middle-aged persons from a Mediterranean country: the EPIC-Spain cohort study. Nutr Metab Cardiovasc Dis. 2012;22:192-9.

10. Trichopoulou A, Costacou T, Bamia C, Trichopoulos D. Adherence to a Mediterranean diet and survival in a Greek population. N Engl J Med. 2003;348:2599-608.

11. da Silva R, Bach-Faig A, Raidó Quintana B, Buckland G, Vaz de Almeida MD, Serra-Majem L. Worldwide variation of adherence to the Mediterranean diet, in 1961-1965 and 2000-2003. Public Health Nutr. 2009;12(9A):1676-84.

12. León-Muñoz LM, Guallar-Castillón P, López-García E, Rodríguez-Artalejo F. Mediterranean diet and risk of frailty in community-dwelling older adults. J Am Med Dir Assoc. 2014;15(12):899-903.

13. Shikany JM, Barrett-Connor E, Ensrud KE, Cawthon PM, Lewis CE, Dam TT, et al. Macronutrients, diet quality, and frailty in older men. J Gerontol A Biol Sci Med Sci. 2014;69:695-701.

14. Talegawkar SA, Bandinelli S, Bandeen-Roche $K$, Chen P, Milaneschi Y, Tanaka T, et al. A higher adherence to a Mediterranean-style diet is inversely associated with the development of frailty in community-dwelling elderly men and women. J Nutr. 2012:142:2161-6.

15. Bollwein J, Diekmann R, Kaiser MJ, Bauer JM, Uter W, Sieber CC, et al. Dietary quality is related to frailty in community-dwelling older adults. J Gerontol A Biol Sci Med Sci. 2013;68:483-89.

16. Zbeida M, Goldsmith R, Shimony T, Vardi H, Naggan L, Shahar DR. Mediterranean diet and functional indicators among older adults in
non-Mediterranean and Mediterranean countries. J Nutr Health Aging. 2014;18:411-8

17. Shahar DR, Houston DK, Hue TF, Lee JS, Sahyoun NR, Tylavsky FA, et al. Adherence to Mediterranean diet and decline in walking speed over 8 years in community-dwelling older adults. J Am Geriatr Soc. 2012:60:1881-8.

18. Rodríguez-Artalejo F, Graciani A, Guallar-Castillón P, León-Muñoz LM, Zuluaga MC, López-García E, et al. Rationale and methods of the study on nutrition and cardiovascular risk in Spain (ENRICA). Rev Esp Cardiol. 2011;64:876-82.

19. EPIC Group of Spain. Relative validity and reproducibility of a diet history questionnaire in Spain. I. Foods. EPIC Group of Spain. European Prospective Investigation into Cancer and Nutrition. Int J Epidemiol. 1997:26:S91-9.

20. Guallar-Castillón P, Sagardui-Villamor J, Balboa-Castillo T, Sala A, Ariza Astolfi MJ, Sarrión Pelous MD, et al. Validity and reproducibility of a Spanish dietary history. PLoS One. 2014;9:e86074.

21. Kleinbaum DG, Muller KE. Variable reduction and factor analysis. In: Applied Regression Analysis and Other Multivariable Methods. Boston, MA: PWS-Kent Publishing Company; 1988.

22. Kim JO, Mueller CW. Factor Analysis: Statistical Methods and Practical Issues. Thousand Oaks, CA: Sage Publications, Inc.; 1978.

23. Fried $L P$, Tangen $C M$, Walston J, Newman AB, Hirsch C, Gottdiener J, et al. Frailty in older adults: evidence for a phenotype. J Gerontol A Biol Sci Med Sci. 2001;56:M146-56.

24. Ruiz-Grosso P, Loret de Mola C, Vega-Dienstmaier JM, Arevalo JM, Chavez K, Vilela A, et al. Validation of the Spanish Center for Epidemiological Studies Depression and Zung Self-Rating Depression Scales: a comparative validation study. PLoS One. 2012;7:e45413.

25. Ottenbacher K, Branch LG, Ray L, Gonzales VA, Peek MK, Hinman MR. The reliability of upper- and lower-extremity strength testing in a community survey of older adults. Arch Phys Med Rehabil. 2002;83:1423-7.

26. Garcia-Garcia FJ, Gutierrez Avila G, Alfaro-Acha A, Amor Andres MS, De Lo Angeles De La Torre Lanza M, Escribano Aparicio MV, et al. The prevalence of frailty syndrome in an older population from Spain. The Toledo Study for Healthy Aging. J Nutr Health Aging. 2011;15:852-6

27. Guralnik JM, Simonsick EM, Ferrucci L, Glynn RJ, Berkman LF, Blazer DG, et al. A short physical performance battery assessing lower extremity function: association with self-reported disability and prediction of mortality and nursing home admission. J Gerontol. 1994;49:M85-94.

28. Gutiérrez-Fisac JL, Guallar-Castillón P, León-Muñoz LM, Graciani A, Banegas $J R$, Rodríguez-Artalejo F. Prevalence of general and abdominal obesity in the adult population of Spain, 2008-2010: the ENRICA study. Obes Rev. 2012;13:388-92.

29. Graciani A, Banegas JR, Guallar-Castillón P, Domínguez-Rojas V, RodríguezArtalejo F. Cognitive assessment of the non-demented elderly community dwellers in Spain. Dement Geriatr Cogn Disord. 2006;21:104-12.

30. Lawton MP, Brody EM. Assessment of older people: self-maintaining and instrumental activities of daily living. Gerontologist. 1969;9:179-86.

31. Hu FB, Rimm EB, Stampfer MJ, Ascherio A, Spiegelman D, Willett WC. Prospective study of major dietary patterns and risk of coronary heart disease in men. Am J Clin Nutr. 2000;72:912-21.

32. Fung $T$, Rimm EB, Spiegelman $D$, Rifai $N$, Tofler GH, Willett WC, et al. Association between dietary patterns and plasma biomarkers of obesity and cardiovascular disease risk. Am J Clin Nutr. 2001;73:61-7.

33. Fung TT, Willett WC, Stampfer MJ, Manson JE, Hu FB. Dietary patterns and the risk of coronary heart disease in women. Arch Intern Med. 2001;161:1857-62.

34. McEvoy CT, Cardwell CR, Woodside JV, Young IS, Hunter SJ, McKinley MC. A posteriori dietary patterns are related to risk of type 2 diabetes: Findings from a systematic review and meta-analysis. J Acad Nutr Diet. 2014. [Epub ahead of print]

35. Esmaillzadeh A, Kimiagar M, Mehrabi Y, Azadbakht L, Hu FB, Willett WC. Dietary patterns, insulin resistance, and prevalence of the metabolic syndrome in women. Am J Clin Nutr. 2007:85:910-8.

36. López-García E, Schulze MB, Fung TT, Meigs JB, Rifai N, Manson JE, et al. Major dietary patterns are related to plasma concentrations of markers of inflammation and endothelial dysfunction. Am J Clin Nutr. 2004;80:1029-35.

37. Akbaraly TN, Singh-Manoux A, Marmot MG, Brunner EJ. Education attenuates the association between dietary patterns and cognition. Dement Geriatr Cogn Disord. 2009;27:147-54. 
38. Kesse-Guyot E, Andreeva VA, Jeandel C, Ferry M, Hercberg S, Galan P. A healthy dietary pattern at midlife is associated with subsequent cognitive performance. J Nutr. 2012;142:909-15.

39. Akbaraly TN, Brunner EJ, Ferrie JE, Marmot MG, Kivimaki M, Singh-Manoux A. Dietary pattern and depressive symptoms in middle age. Br J Psychiatry. 2009;195:408-13

40. Lai JS, Hiles S, Bisquera A, Hure AJ, McEvoy M, Attia J. A systematic review and meta-analysis of dietary patterns and depression in communitydwelling adults. Am J Clin Nutr. 2014;99:181-97.

41. Torres SJ, Lautenschlager NT, Wattanapenpaiboon N, Greenop KR, Beer C, Flicker L, et al. Dietary patterns are associated with cognition among older people with mild cognitive impairment. Nutrients. 2012:4:1542-51.

42. Jacka FN, Cherbuin N, Anstey KJ, Butterworth P. Dietary patterns and depressive symptoms over time: examining the relationships with socioeconomic position, health behaviours and cardiovascular risk. PLoS One. 2014;9:e87657.

43. Schulze MB, Hoffmann K, Manson JE, Willett WC, Meigs JB, Weikert C, et al. Dietary pattern, inflammation, and incidence of type 2 diabetes in women. Am J Clin Nutr. 2005;82:675-84.

44. Stenholm S, Strandberg TE, Pitkälä K, Sainio P, Heliövaara M, Koskinen S. Midlife obesity and risk of frailty in old age during a 22-year follow-up in men and women: the Mini-Finland Follow-up Survey. J Gerontol A Biol Sci Med Sci. 2014;69:73-8.

45. Barzilay Jl, Blaum C, Moore T, Xue QL, Hirsch CH, Walston JD, et al. Insulin resistance and inflammation as precursors of frailty: the Cardiovascular Health Study. Arch Intern Med. 2007;167:635-41.

46. Tang Z, Wang C, Song X, Shi J, Mitnitski A, Fang X, et al. Co-occurrence of cardiometabolic diseases and frailty in older Chinese adults in the Beijing Longitudinal Study of Ageing. Age Ageing. 2013;42:346-51.

47. Gale CR, Baylis D, Cooper C, Sayer AA. Inflammatory markers and incident frailty in men and women: the English Longitudinal Study of Ageing. Age (Dordr). 2013;35:2493-501.

48. Raji MA, Al Snih S, Ostir GV, Markides KS, Ottenbacher KJ. Cognitive status and future risk of frailty in older Mexican Americans. J Gerontol A Biol Sci Med Sci. 2010;65:1228-34.

49. Han ES, Lee Y, Kim J. Association of cognitive impairment with frailty in community-dwelling older adults. Int Psychogeriatr. 2014;26:155-63.

50. Lohman M, Dumenci L, Mezuk B. Sex differences in the construct overlap of frailty and depression: evidence from the Health and Retirement Study. J Am Geriatr Soc. 2014;62:500-5.

51. Robinson SM, Jameson KA, Batelaan SF, Martin HJ, Syddall HE, Dennison EM, et al. Diet and its relationship with grip strength in community-dwelling older men and women: the Hertfordshire cohort study. J Am Geriatr Soc 2008:56:84-90.

52. Trichopoulou A, Bamia C, Trichopoulos D. Anatomy of health effects of Mediterranean diet: Greek EPIC prospective cohort study. BMJ. 2009;338: b2337.

53. Gea A, Bes-Rastrollo M, Toledo E, Garcia-Lopez M, Beunza JJ, Estruch R, et al. Mediterranean alcohol-drinking pattern and mortality in the SUN (Seguimiento Universidad de Navarra) Project: a prospective cohort study. Br J Nutr. 2014;111:1871-80.

54. Pozzato G, Moretti M, Franzin F, Crocè LS, Lacchin T, Benedetti G, et al. Ethanol metabolism and aging: the role of "first pass metabolism" and gastric alcohol dehydrogenase activity. J Gerontol A Biol Sci Med Sci. 1995;50:B135-41.

55. Estruch R, Ros E, Salas-Salvadó J, Covas MI, Corella D, Arós F, et al. Primary prevention of cardiovascular disease with a Mediterranean diet. N Engl J Med. 2013;368:1279-90.

56. de Lorgeril M, Salen P, Martin JL, Monjaud I, Delaye J, Mamelle N. Mediterranean diet, traditional risk factors, and the rate of cardiovascular complications after myocardial infarction: final report of the Lyon Diet Heart Study. Circulation. 1999;99:779-85.

57. Allès B, Samieri C, Féart C, Jutand MA, Laurin D, Barberger-Gateau P. Dietary patterns: a novel approach to examine the link between nutrition and cognitive function in older individuals. Nutr Res Rev. 2012;25:207-22
58. León-Muñoz LM, Guallar-Castillón P, Graciani A, López-García E, Mesas AE, Aguilera MT, et al. Adherence to the Mediterranean diet pattern has declined in Spanish adults. J Nutr. 2012;142:1843-50.

59. Ministry of Health, Social Services and Equity. National Strategy for Nutrition, Physical Activity and Prevention of Obesity in Spain (NAOS strategy). 2014. http://www.naos.aesan.msssi.gob.es/. Accessed July 30, 2014.

\section{Submit your next manuscript to BioMed Central and take full advantage of:}

- Convenient online submission

- Thorough peer review

- No space constraints or color figure charges

- Immediate publication on acceptance

- Inclusion in PubMed, CAS, Scopus and Google Scholar

- Research which is freely available for redistribution

Submit your manuscript at www.biomedcentral.com/submit 